\title{
Utilização do fungo Pycnoporus sanguineus para biopolpação de madeira
}

\author{
Pycnoporus sanguineus fungus \\ as wood biopulping
}

\author{
Débora Duarte Ribes ${ }^{1}$, Paula Zanatta ${ }^{1}$, Ezequiel Gallio ${ }^{1}$, \\ Tainise Lourençon ${ }^{2}$, Rafael Beltrame ${ }^{1}$, \\ Cristiane Pedrazzi ${ }^{3}$, Darci Alberto Gatto ${ }^{1}$.
}

\footnotetext{
${ }^{1}$ Centro de desenvolvimento tecnológico, EIM/PPGCEM/UFPel CEP: 96010-290, Pelotas, Rio Grande do Sul, Brasil. ${ }^{2}$ Centro de Ciências Florestais e da Madeira (PPGEF), Universidade Federal do Paraná, 900, Av. Lothário Meissner, CEP: 80210-170, Curitiba, Paraná, Brasil.

${ }^{3}$ Departamento Ciências Florestais, Universidade Federal de Santa Maria, Av. Roraima ${ }^{\circ}{ }^{1000}$, Cidade Universitária Bairro Camobi, CEP 97105900, Santa Maria, Rio Grande do Sul, Brasil.

e-mail: deboraribes@hotmail.com, zanatta_paula@hotmail.com, egeng.florestal@gmail.com, tainise@gmail.com, beltrame.rafael@yahoo.com.br, cpedrazzi@terra.com,br, darcigatto@pq.cnpq.br
}

\section{RESUMO}

O estudo teve como objetivo avaliar a eficiência do fungo Pycnoporus sanguineus como pré-tratamento para biopolpação de três espécies de eucalipto. As madeiras ficaram expostas ao fungo por 30, 60 e 90 dias, em condições favoráveis. Para verificar a eficiência da deslignificação causada pelo fungo foram quantificados: perda de massa, teor de extrativos, lignina insolúvel e modificação morfológica da fibra. Os resultados demonstraram que a madeira de Eucalyptus globulus no período de 90 dias, foi a mais promissora para o prétratamento fúngico, onde nesse período foi o que ocorreu maior deslignificação. De modo geral, foi possível concluir que o fungo Pycnoporus sanguineus promoveu a degradação de lignina o que o torna um processo em potencial para a indústria de celulose e papel a qual necessita a retirada desses polímeros sempre visando uma produção mais econômica e ambientalmente viável.

Palavras-chave: eucalipto, fungos de podridão branca, fibras, deslignificação.

\begin{abstract}
The objective of this study was to evaluate lignin removal efficiency of three eucalypt species through Pycnoporus sanguineus fungus inoculation. The wood samples were inoculated at different periods: 30,60 and 90 days. To verify the efficiency of the delignification caused by the fungus were quantified: mass loss, extractives, acid insoluble lignin and morphological modification of inoculated and not inoculated fiber. The results showed that Eucalyptus globulus wood in the 90-day period was the most promising for fungal pretreatment, where delignification occurred the most. In general, it was possible to concude that the fungus Pycnoporus sanguineus is efficient in the degradation of lignin, which makes it a potential process for the pulp and paper industry, which desires the removal of these polymers always aiming at the most economical production and environmental feasible.
\end{abstract}

Keywords: eucalypt, white rot fungi, fibers, delignification.

\section{INTRODUÇÃO}

O processo de extração de celulose da madeira, conhecida como polpação, é realizado por sistemas mecânicos e químicos [1]. Contudo, ambos consomem altos níveis de energia elétrica, e em maioria originam elevada produção de resíduos químicos, que implicam na poluição ambiental. A quantidade de resíduos sólidos gerados durante o processo de produção da celulose pode chegar a $800 \mathrm{~kg}$ para cada tonelada [2], o que acarretou em mudanças e novas exigências na legislação quanto ao tratamento e qualidade dos efluentes industriais.

Atualmente, certificações ambientais e florestais, bem como certificados de conformidade em termos de reagentes químicos, matérias-prima, emissões de gases de efeito estufa, uso da água e origem das fibras, 
são instrumentos que contribuem para conformidade ambiental de uma indústria [3]. Com a maior rigidez nas normas ambientais recomenda-se urgentes alterações do processo produtivo [4]. Sendo assim, busca-se métodos alternativos para extração de celulose, de menor agressividade e que possam minimizar os prejuízos ambientais, os efluentes gerado no processo de branqueamento que possui alto teor de dioxinas originadas do cloro usado.

Uma alternativa de produção que visa à redução das cargas poluentes nas indústrias de celulose e papel é o processo de biopolpação. Este, antecede a produção de polpa mecânica ou química, isto é, a extração de celulose ocorre por meio de fungos lignolíticos, causadores de podridão branca, devido à capacidade destes degradarem a lignina seletivamente e deixarem a celulose relativamente intacta $[5,6,7]$.

Os benefícios esperados pela utilização desse tratamento estão na qualidade da fibra obtida, acarretando assim em melhorias nas propriedades mecânicas, preservando a morfologia das fibras e maior nível de fibrilação [4]. Foelkel [8], atribui essas características ao amolecimento dos cavacos, podendo ter sido ocasionado pela ruptura preferencial de ligações ( $\beta-0-4$, reduzindo a massa molar da lignina). Kausar [9], descreve que o fungo proporciona o aumento do ponto de saturação das fibras e assim facilitando o refino por meio de refinadores de disco.

Neste contexto, o objetivo deste estudo foi avaliar a eficiência da biopolpação utilizando o fungo de podridão branca Pycnoporus sanguineus como pré-tratamento de cavacos de madeira de Eucalyptus utilizados na produção de polpa celulósica.

\section{MATERIAIS E MÉTODOS}

\subsection{Procedência e preparo dos corpos de prova}

As espécies utilizadas foram Eucalyptus globulus, Eucalyptus urograndis e Eucalyptus cloeziana com aproximadamente sete anos de idade, doadas pelo Laboratório de Celulose e Papel da Universidade Federal de Viçosa, Minas Gerais, as quais estavam em forma de cavacos. Essas espécies foram escolhidas por se tratarem das principais madeiras utilizadas como matéria-prima em indústrias de celulose no Brasil.

Por meio de uma classificação manual e visual, fez-se a retirada de cavacos superdimensionados, com presença de nós e de cunhas. Os cavacos selecionados foram secos $12 \%$ e armazenados em sacos de polietileno, para uniformização e conservação do teor de umidade. Separou-se quatro lotes de $200 \mathrm{~g}$ para cada espécie, para inoculação do micélio do fungo Pycnoporus sanguineus, cedido pelo Laboratório de Produtos Florestais (LPF) do Serviço Florestal Brasileiro, Brasília. As análises posteriormente descritas foram realizadas periodicamente, conforme Tabela 1.

Tabela 1: Nomenclatura designada às espécies utilizadas no experimento e tempo de exposição ao fungo Pycnoporus sanguineus.

\begin{tabular}{|c|c|c|c|c|}
\hline Espécie & 0 dias & 30 dias & 60 dias & 90 dias \\
\hline Eucalyptus globulus & GT0 & GT1 & GT2 & GT3 \\
\hline $\begin{array}{l}\text { Eucalyptus urograndis (E. grandis x E. } \\
\text { urophylla) }\end{array}$ & UT0 & UT1 & UT2 & UT3 \\
\hline Eucalyptus cloeziana & СТ0 & CT1 & $\mathrm{CT} 2$ & CT3 \\
\hline
\end{tabular}

\subsection{Inoculação do fungo nas madeiras}

Os quatro lotes de cada espécie anteriormente secos ao ar, foram submersos em água por 48 horas, após foram autoclavados a $120^{\circ} \mathrm{C}$ e pressão de $1 \mathrm{~atm}$, por 30 minutos. Após a esterilização dos mesmos, iniciou-se a inoculação do fungo.

Foram adicionados três discos de fungo (com raio de $10 \mathrm{~mm}$ ) nos diferentes lotes, os quais continham 
os cavacos previamente selecionados e algodão para manter a aeração. Esses permaneceram armazenados em câmara climatizada com temperatura de $25{ }^{\circ} \mathrm{C}$ e $65 \%$ de umidade relativa, por um período de 30, 60 e 90 dias.

Vale ressaltar que o período correspondente a zero dias não recebeu o micélio do fungo.

Decorrido o período de ataque dos fungos, retirou-se os cavacos dos sacos de polietileno e removeu-se os micélios acumulados na superfície da madeira.

\subsection{Caracterização das madeiras expostas ao fungo}

\subsubsection{Perda de massa}

Após o período de exposição ao ataque dos fungos, verificou-se o grau de resistência natural das madeiras estudadas por meio da perda de massa calculada pela diferença entre a massa seca antes e após a exposição ao fungo.

\subsubsection{Caracterização física e química}

Para a análise química, as amostras nos diferentes tempos de exposição, foram moídas separadamente em moinho Willey, até se transformarem em serragem. As amostras moídas foram classificadas em peneiras de 40/60 mesh, através de um peneiramento manual, das quais se selecionou as que ficaram retidas na peneira de 60 mesh. Após esta seleção, realizaram-se as análises químicas de teores de extrativos e lignina Klason, com duplicata para todos os lotes.

Para a determinação do teor de extrativos utilizou-se 2,0 g de amostra anidra, a qual foi seca em estufa a $100{ }^{\circ} \mathrm{C}$ por $24 \mathrm{~h}$. Como solventes, utilizou-se diclorometano e etanol/tolueno (1:2), de acordo com a norma TAPPI T204 om-88. A quantidade de lignina insolúvel em ácido foi determinada de acordo com a norma TAPPI T222 om-98, a partir de 1,0 g de amostra anidra e livre de extrativos.

\subsection{Morfologia das fibras}

Para as análises anatômicas das fibras utilizou-se o processo de maceração por meio do método Ácido Nítrico-Acético. A solução macerante contendo ácido acético e ácido nítrico (5:1), foi posteriormente diluída em água destilada, na proporção 2:1.

Com o auxílio do microscópio estereoscópio TBN-04T-PL da marca OPTON e do programa MIPRO STANDARD V1.1, foi possível a visualização das fibras e a mensuração das dimensões individuais. Analisou-se o comprimento e o diâmetro da parede celular de 30 fibras de cada lote nos diferentes tempos de exposição fúngica. Estas variáveis foram analisadas por meio de análise de variância (ANOVA). Quando a hipótese nula foi rejeitada, os valores médios foram comparados pelo teste Tukey com nível de confiança de $95,0 \%$.

\section{RESULTADOS}

\subsection{Perda de massa}

A biopolpação resultou em perda de massa para todas as espécies estudadas (Figura 1), o que já era esperado devido a degradação de alguns componentes químicos da madeira pelo fungo, como a lignina. Sabe-se que os fungos de podridão branca possuem uma seletividade na degradação da lignina, Foelkel [8] relata que o fungo Pycnoporus sanguineus inicia a degradação na madeira pelos elementos de vasos e parênquima axial e em um estágio mais avançado pelas células do parênquima radial e elementos fibrosos. Sendo assim verificou-se uma perda de massa considerável, de aproximadamente 50\%, classificando-se assim essas madeiras como de baixa resistência biológica, o que a torna interessante como um pré-tratamento para polpação celulósica. 


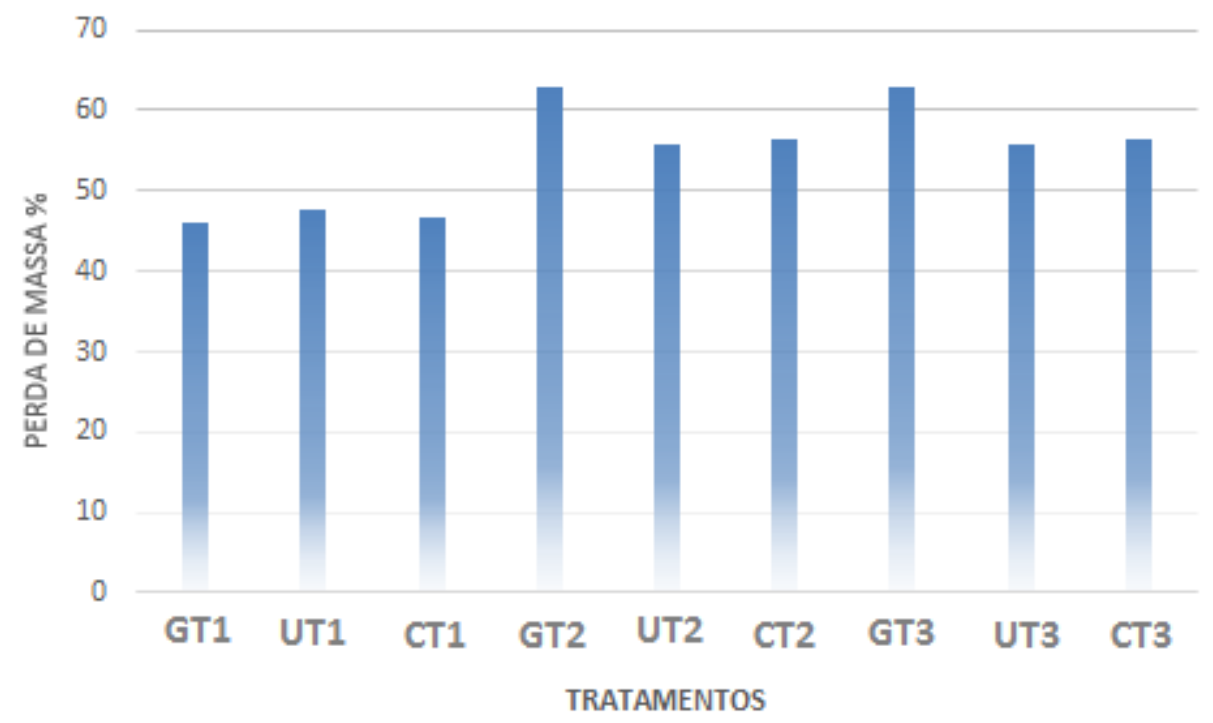

Figura 1: Perda de massa das madeiras de eucalipto tratadas com o fungo. Onde: GT1 = Eucalyptus globulus 30 dais; $\mathrm{UT} 1=$ Eucalyptus $x$ urugrandis 30 dias; CT1 = Eucayptus cloeziana 30 dias; GT2 = Eucalyptus globulus 60 dias; UT2= Eucalyptus $x$ urugrandis 60 dias; CT2 = Eucayptus cloeziana 60 dias; GT3 = Eucalyptus globulus 90 dias; UT3 = Eucalyptus $x$ urugrandis 90 dias; CT3 = Eucayptus cloeziana 90 dias.

Com relação à eficiência dos tratamentos das madeiras com o fungo, pode-se verificar que aos 60 e 90 dias de inoculação, de uma forma geral, resultou em uma perda constante de massa. Esse resultado pode ser explicado com base no trabalho desenvolvido por Uzan [10], no qual foi concluído que nos 30 primeiros dias de inoculação o fungo está se adaptando ao ambiente no qual está se desenvolvendo, e que após os 60 dias o agente biológico poderá se encontrar praticamente saturado, reduzindo assim a atividade. Com base nos dados analisados o tempo de 60 dias vem ser o mais indicado, visto que reduziria o tempo e o gasto em energia.

Comparando a perda de massa entre as espécies aos 60 dias, pode-se observar que Eucalyptus globulus resultou em $62,95 \%$, mostrando ser a madeira mais atacada pelo fungo, seguida pelo Eucalyptus cloeziana $(56,39 \%)$ e finalmente pelo Eucalyptus urograndis com $55,84 \%$.

\subsection{Caracterização química}

Os teores de extrativos encontrados na Tabela 2 para as três espécies estão de acordo com os valores encontrados na literatura para o gênero Eucalyptus, que são de aproximadamente 2\% [11]. Alguns extrativos da madeira são quimicamente e estruturalmente semelhantes a lignina [4], sendo, por isso, possível o ataque do fungo nessas estruturas causando a degradação e remoção.

Tabela 2: Teor de extrativos das madeiras expostas ao fungo Pycnoporus sanguineus

\begin{tabular}{ccccc}
\hline \multirow{2}{*}{ Espécie } & \multicolumn{5}{c}{ Média (\%) } \\
\cline { 2 - 5 } & 0 dias & 30 dias & 60 dias & 90 dias \\
\hline Eucalyptus globulus & 1,42 & 1,07 & 0,66 & 0,41 \\
\hline $\begin{array}{c}\text { Eucalyptus urograndis (E. grandis } x \\
\text { E. urophylla) }\end{array}$ & 1,81 & 1,50 & 1,41 & 1,37 \\
\hline Eucalyptus cloeziana & 1,45 & 0,81 & 1,70 & 0,25 \\
\hline Média & $1,63(0,25) \mathrm{ab}$ & $1,13(0,35) \mathrm{a}$ & $1,26(0,53) \mathrm{b}$ & $0,68(0,60) \mathrm{ab}$ \\
\hline
\end{tabular}

Onde: Valores entre parênteses se referem ao desvio padrão e médias com letras iguais não diferem estatisticamente pelo teste Tukey com nível de confiança de 95,0\%.

Os extrativos foram removidos no decorrer do tempo pelo fungo nas madeiras de Eucalyptus globulus e Eucalyptus urograndis, ao contrário da madeira de Eucalyptus cloeziana (60 dias). Foelkell [4] descreve que os microorganismos alimentam-se dos extrativos podendo dessa maneira ocupar os espaços correspondentes a estes e, portanto, ser quantificado nas análises químicas.

Comparando os tempos sem inoculação e os de inoculação com o fungo, percebe-se de maneira geral, 
que em todos os tempos de inoculação do fungo ocorreu redução no teor de extrativos nas amostras, com perdas significativas para o tempo T3. As madeiras de Eucalyptus urograndis (E. grandis $x$ E. urophylla) e de Eucalyptus globulos apresentaram perda de extrativos em todos os períodos. O Eucalyptus cloeziana teve perda nos primeiros 30 dias, sendo que para os demais tempos pode-se desconsiderar o processo de biopolpação, devido aos microorganismos terem sido quantificados nas análises.

Os extrativos são componentes químicos indesejáveis em processos de cozimento kraft, devendo ser removidos durante a polpação da madeira [12]. A permanência de uma porcentagem de extrativos podem se aglomerar em etapas posteriores do processo da pasta de celulose, formando assim depósitos denominados de "pitch". Assim, o pré-tratamento com fungo em um período de 90 dias auxiliaria na remoção dos extrativos, diminuindo, consequentemente, a carga de álcali necessária para o sistema de polpação.

\subsection{Teores de lignina}

Os valores de lignina Klason obtidos das madeiras estudadas são semelhantes aos encontrados na literatura (Tabela 3). Em trabalhos já realizados por Silvério et al. [13] e Foelkel [14], foram obtidos valores de lignina para madeiras de eucaliptos com sete anos de idade na faixa de 21 a $26 \%$. Segundo Ek [15], a composição química da madeira varia conforme a idade fisiológica das fibras, além disso, afirma que quando o processo de lignificação é completado, geralmente coincide com a morte da célula, formando o que se denomina de tecido de resistência. Assim, o teor de lignina obtido pelas madeiras desse estudo é explicado pela idade das madeiras.

Tabela 3: Teor de lignina das madeiras expostas ao fungo Pycnoporus sanguineus

\begin{tabular}{ccccc}
\hline Espécie & \multicolumn{5}{c}{ Média (\%) } \\
\hline & 0 dias & 30 dias & 60 dias & 90 dias \\
\hline Eucalyptus globulus & 26,6 & 24,9 & 24,7 & 24,0 \\
\hline $\begin{array}{c}\text { Eucalyptus urograndis }(E . \\
\text { grandis } x \text { E. urophylla) }\end{array}$ & 26,2 & 24,8 & 24,6 & 24,0 \\
\hline Eucalyptus cloeziana & 25,1 & 24,9 & 23,8 & 23,3 \\
\hline Média & $25,9(0,78) \mathrm{a}$ & $24,8(0,06) \mathrm{ab}$ & $24,3(0,49) \mathrm{b}$ & $23,7(0,40) \mathrm{c}$ \\
\hline
\end{tabular}

Onde: Valores entre parênteses se referem ao desvio padrão e médias com letras iguais não diferem estatisticamente pelo teste Tukey com nível de confiança de 95,0\%.

Com relação ao tratamento fúngico, observa-se que em todas as espécies de Eucalyptus spp. ocorreu redução do teor de lignina com a inoculação do fungo, mas durante os tempos de inoculação com 30 a 60 dias não ocorreram remoção significativas de lignina, diferentemente do tempo de 90 dias. Os fungos de degradação branca são os únicos microorganismos capazes de converter a lignina em dióxido de carbono e água, reduzindo, consequentemente, a quantidade deste componente químico na madeira. Esta capacidade é atribuída ao sistema enzimático extracelular produzido por esses fungos, os quais são capazes de atuar sobre uma grande variedade de compostos xenobióticos com características lignolíticas [14]. De acordo com o mesmo autor, a eficiente remoção da lignina em polpas celulósicas é necessária, pois fragmentos residuais desse componente químico causam cor, dificultando o processo de branqueamento da celulose.

A eficiência de remoção da lignina pelo fungo aumentou com o acréscimo dos dias de inoculação, ou seja, o fungo removeu uma quantidade maior de lignina no período de 90 dias de inoculação (Tabela 4). É possível afirmar que o Eucalyptus globulus mostrou ser a espécie mais atacada pelo fungo, seguido por Eucalyptus urograndis (E. grandis $x$ E. urophylla), ambos no $3^{\circ}$ período de inoculação. Aparentemente, a espécie de Eucalyptus cloeziana foi a menos atacada pelo fungo, o que pode ser corroborado pela menor perda de massa (Figura 1), podendo ser confirmada pela afirmação de Kausar. [9], em que o fungo possui uma maior preferência de ruptura das ligações ( $\beta-0-4)$, reduzindo assim a massa molar da lignina. 
Tabela 4: eficiência de remoção da lignina pelo fungo nas madeiras de Eucalyptus.

\begin{tabular}{|c|c|c|c|}
\hline \multirow[t]{2}{*}{ Espécie } & \multicolumn{3}{|c|}{ Eficiência de remoção (\%) } \\
\hline & 30 dias & 60 dias & 90 dias \\
\hline Eucalyptus globulus & 6,4 & 7,1 & 9,8 \\
\hline Eucalyptus urograndis (E. grandis $x$ E. urophylla) & 5,3 & 6,1 & 8,4 \\
\hline Eucalyptus cloeziana & 0,8 & 5,2 & 7,2 \\
\hline
\end{tabular}

\subsection{Morfologia das fibras}

Verificou-se o comprimento e a espessura da parede celular das fibras antes e após os períodos de exposição fúngica, as quais segundo Foelkel [14] são as principais características morfológicas das fibras de papel. O comprimento da fibra do papel influencia na resistência superficial, resistência a umidade e ao rasgo. As Figuras 2 a 4 mostram a morfologia das amostras testemunhas e de 90 dias de inoculação do fungo, prétratamento considerado mais adequado a partir dos resultados.
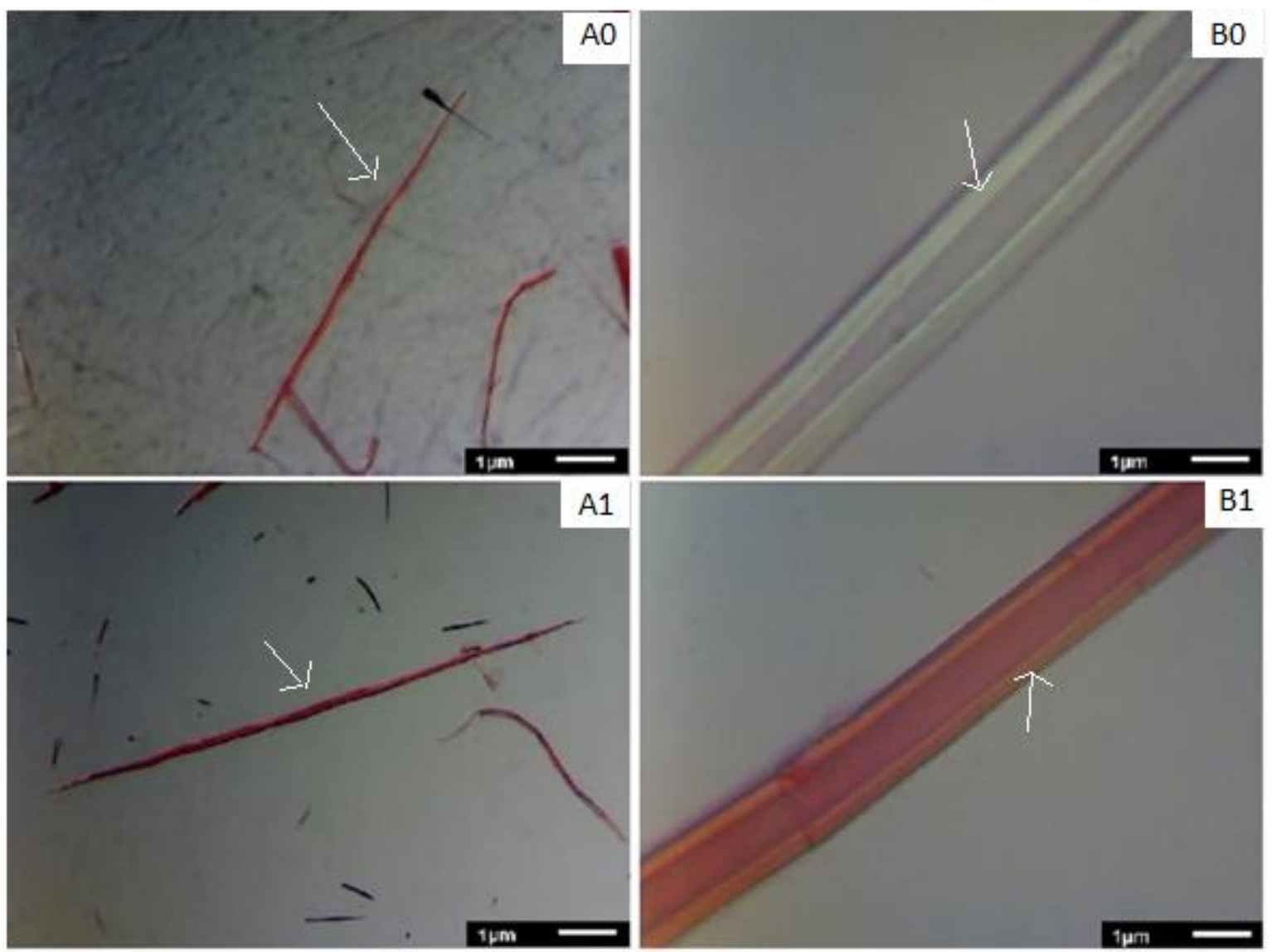

Figura 2: Morfologia das amostras de Eucalyptus globulus. Onde: A0 = comprimento testemunha (GT0), A1 = comprimento com 90 dias de inoculação (GT3), B0 = espessura da parede da fibra de testemunha (GT0), B1 = espessura da parede da fibra de testemunha (GT3). 




Figura 3: Morfologia das amostras de Eucalyptus urograndis (E. grandis $x$ E. urophylla). Onde: A0 = comprimento testemunha (UT0), A1 = comprimento com 90 dias de inoculação (UT3), B0 = espessura da parede da fibra de testemunha (UT0), B1 = espessura da parede da fibra de testemunha (UT3). 



Figura 4: Morfologia das amostras de Eucalyptus cloeziana. Onde: A0 = comprimento testemunha (CT0), A1 = comprimento com 90 dias de inoculação (CT3), B0 = espessura da parede da fibra de testemunha (CT0), B1 = espessura da parede da fibra de testemunha (CT3).

$\mathrm{Na}$ Tabela 5 pode-se observar que conforme o tempo de inoculação os comprimentos foram reduzidos, mas entre os tempos T0 e T1 não obtiveram diferenças significativas assim como entre os tempos T2 e T3. Conforme relatado em bibliografias os comprimentos de Eucalyptus globulus ficam em torno de 7,00 a 7,50 um, conforme pode ser observado, no tempo após 90 dias de exposição ao fungo, os comprimentos das fibras ainda se encontram dentro da média estabelecida por Pedrazzi [16].

Tabela 5: valores do comprimento das fibras das madeiras nos 4 tempos analisados

\begin{tabular}{|c|c|c|c|c|}
\hline \multirow{2}{*}{ Espécie } & \multicolumn{4}{|c|}{ Comprimento $\mu \mathrm{m}$} \\
\hline & 0 dias & 30 dias & 60 dias & 90 dias \\
\hline Eucalyptus globulus & 1,09 & 1,08 & 9,32 & 9,25 \\
\hline $\begin{array}{c}\text { Eucalyptus urograndis (E. grandis } x \\
\text { E. urophylla) }\end{array}$ & 1,14 & 1,02 & 8,54 & 8,34 \\
\hline Eucalyptus cloeziana & 1,09 & 1,04 & 9,74 & 8,33 \\
\hline Média e Desvio Padrão & $1,115(0,03) \mathrm{b}$ & $1,03(0,03) \mathrm{b}$ & $9,14(0,61) \mathrm{a}$ & $8,33(0,53) \mathrm{a}$ \\
\hline
\end{tabular}

Onde: Valores entre parênteses se referem ao desvio padrão e médias com letras iguais não diferem estatisticamente pelo teste Tukey com nível de confiança de 95,0\%.

Fibras com paredes celulares espessas tem uma alta capacidade ao rasgo, tração baixa, folha porosa, baixa opacidade, alta absorção de água, rugosidade superficial e população fibrosa baixa, diferentemente das 
fibras de paredes celulares finas que possuem alta tração, baixo rasgo, folha densa, maior resistência a umidade, alta opacidade, população fibrosa alta. Conforme Foelkel [17], as espessuras para Eucalyptus globulus e Eucalyptus urograndis é de 4 a $5 \mu \mathrm{m}$, a Tabela 6 relata que em todos os tempos estudados as espessuras estão dentro do estudo feito pelo mesmo autor.

As diferenças obtidas em relação ao tempo de 90 dias pode ter ocorrido pelo fato de ser o maior tempo de inoculação com o fungo, sendo assim degradando as características morfológicas das fibras de madeira, mas nenhuma dessas características afetam a produção de polpa e papel.

Tabela 6: Valores médios da espessura da parede das fibras das madeiras nos 4 tempos.

\begin{tabular}{ccccc}
\hline \multirow{2}{*}{ Espécie } & \multicolumn{4}{c}{ Espessura $\boldsymbol{\mu m}$} \\
\cline { 2 - 4 } & 0 dias & 30 dias & 60 dias & 90 dias \\
\hline Eucalyptus globulus & 7,02 & 5,57 & 5,38 \\
\hline Eucalyptus urograndis (E. grandis $x$ & 5,24 & 4,94 & 3,13 \\
E. urophylla) & & & 4,66 & 3,28 \\
\hline Eucalyptus cloeziana & 4,69 & 4,64 & 4,03 & $3,205(0,72)$ ab \\
\hline Média e Desvio Padrão & $4,96(2,88)$ a & $4,79(0,47)$ ab & $4,345(0,67)$ ab & \\
\hline Onde: valores entre parênteses se referem ao desvio padrão e médias com letras iguais não diferem estatistica-
\end{tabular}
mente pelo teste tukey com nível de confiança de $95,0 \%$.

\section{CONCLUSÕES}

Consegue-se concluir que a partir desse estudo o processo de biopolpação como pré-tratamento promoveu a degradação da lignina, devido a seletividade do fungo de podridão branca. As maiores diminuições de lignina foram para a madeira de Eucalyptus globulus seguida de Eucalyptus urograndis (E. grandis $x$ E. urophylla) $e$ Eucalyptus cloeziana todos aos 90 dias. Entretanto, o tempo de 90 dias também foi o que mais modificou a morfologia das fibras devido a degradação das paredes celulares das fibras.

\section{AGRADECIMENTOS}

Os autores agradecem a Universidade Federal de Pelotas (UFPel) e ao Conselho Nacional de Desenvolvimento Científico e Tecnológico (CNPq), pelo suporte financeiro.

\section{BIBLIOGRAFIA}

[1] ABTCP- ASSOCIAÇÃO BRASILEIRA DE PASTA DE PAPEL DE PAPEL., 002. Métodos de ensaio. São Paulo, 2002.

[2] ASSOCIAÇÃO BRASILEIRA DE CELULOSE E PAPEL (BRACELPA). Desempenho do setor em 2010. São Paulo, 2010. Disponível em <http://www.bracelpa.org.br/bra/estatisticas/pdf/booklet/booklet.pdf> Acesso em: 28 ago. 2017.

[3] FOELKEL, C. Aspectos tecnológicos da evolução do processo de produção de celulose e papel, v31, 2011.

[4] FOELKEL, C.; Aplicações da Biotecnologia em Processos Industriais de Fabricação de Celulose de Eucalipto, livro e boletim informativo on-line, 2013

[5] AGUIAR, A., FERRAZ, A. "Mecanismos envolvidos na biodegradação de materiais lignocelulósicos e aplicações tecnológicas correlatadas”, Química Nova, v. 34, n. 10, pp. 1729-1738, 2010.

[6] CUNHA, G. G. S., et al. "Linoleic acid peroxidation and lignina degradation by enzymes produced by Ceriporiopsis subermispora grown on wood or um submerged liquid culturs", Enzyme na Microbial Technology, v. 46, pp. 254-255, 2010.

[7] DWIVEDI, P., VIVEKANAND, V., PAREEK, N., et al., "Bleach enhancement of mixed wood pulp by xylanase-laccase concoction derived through co-cultre strategy", Appllied Biochemustry and Biotechnology, v.160, pp. 233-235, 2010. 
[8] FOELKEL, C . Fibras de eucalipto e as qualidades exigidas na polpa kraft para fabricação de papel, livro e boletim informativo on-line, 2007

[9] KAUSAR, H., SARIAH, M., SAUD, H.M., et al., "Development of compatible lignocellulytic fungal consortium fo rapid composting of rice straw", International Biodeterioratio and Biodegradatio, v.64, n.7, 2010 .

[10] UZAN, E., NOUSIAINEN P, BALLAND V., et al., "High redox potenctial laccases from the ligninolytic fungi Pycnoporus Coccineus and Pycnoporus sanguineus suitable for white biotechology: from gene cloning to enzyme characterization and applications", Journal of Applied Microbiology, v. 108, n.6, 2010.

[11] SALAZAR, C., MENDONÇA, R.T., BAEZA, J., et al., "Kraft Pulping and ECF bleaching of Eucalyptus globulus pretreated by the whiterot fungus Ceriporiopsis subvermispora", Acta Scientiarum, v.34, n.3, pp.277-281, 2012.

[12] ELISASHVILI, V., KACHLISHVILI, E., KHARDZIANI, T., et al., "Effect of aromatic compounds on the roduction of laccase and manganese peroxidase by whote-rot Basidiomycetes", Journal of Industrial Microbiology and Biotechnology, v. 37, n. 10, 2010.

[13] SILVERIO, F. "Metodologia de extração e determinação do conteúdo de extrativos em madeira", Rev. Árvore, v.30, n.6, pp.1009-1016, 2006.

[14] FOELKEL, C. As biorrefinarias integradas no setor brasileiro de fabricação de celulose e papel de eucalipto, Eucalyptus Online Book, 2012.

[15] EK, M., GELlERSTEDT, G., HENRIKSSON, G. "Pulp and Paper Chemistry and Technology: Fibre and Polymer Technology”, Sweden: School of Chemical Science and Engineering, v.2, 2009.

[16] PEDRAZZI, C. "Influência de xilano na produção e propriedades de polpas de eucalipto para papéis", Tese de D.Sc., Engenharia Florestal pela Universidade Federal de Viçosa, Viçosa-MG, 2009.

[17] FOELKEL, C. Individualização de fibras de madeira de eucalipto para a produção de polpa Kraft. Eucalipto, Online Book \& Newsletter, 2009. 